\title{
Hospitalised and Fatal Head Injuries in Viti Levu, Fiji: Findings from an Island-Wide Trauma Registry (TRIP 4)
}

\author{
Bridget Kool ${ }^{a}$ Naina Raj ${ }^{b}$ Iris Wainiqolo ${ }^{c}$ Berlin Kafoa $^{c}$ Eddie McCaig ${ }^{c}$ \\ Shanthi Ameratunga ${ }^{a}$ \\ a Section of Epidemiology and Biostatistics, School of Population Health, The University of Auckland, and \\ bEnvironmental Health Protection Team, Auckland Regional Public Health Service, Auckland, New Zealand; \\ ${ }^{c}$ College of Medicine, Nursing and Health Science, Fiji National University, Suva, Fiji
}

\section{Key Words}

Head injuries · Epidemiology • Traumatic brain injury •

Surveillance $\cdot$ Fiji

\begin{abstract}
Background: Globally, head injury is a substantial cause of mortality and morbidity. A disproportionately greater burden is borne by low- and middle-income countries. The incidence and characteristics of fatal and hospitalised head injuries in Fiji are unknown. Methods: Using prospective data from the Fiji Injury Surveillance in Hospital system, the epidemiology of fatal and hospitalised head injuries was investigated (2004-2005). Results: In total, 226 hospital admissions and 50 fatalities (66\% died prior to admission) with a principal diagnosis of head injury were identified (crude annual rates of 34.7 and 7.7/100,000, respectively). Males were more likely to die and be hospitalised as a result of head injury than females. The highest fatality rate was among those in the 30-44-year age group. Road traffic crashes were the leading causes of injuries resulting in death (70\%), followed by 'hit by person or object' and falls ( $14 \%$ each). Among people admitted to hospital, road traffic crashes (34.5\%) and falls (33.2\%) were the leading causes of injury. The leading cause of head injuries in children was falls, in 15-29-year-olds road
\end{abstract}

traffic crashes, and in adults aged 30-44 years or 45 years and older 'hit by person or object'. Among the two major ethnic groups, Fijians had higher rates of falls and 'hit by person or object' and Indians higher rates for road traffic crashes. There were no statistically significant differences between the overall rates of head injuries or the fatal and nonfatal rates among Fijians or Indians by gender following age standardisation to the total Fijian national population. Conclusion: Despite underestimating the overall burden, this study identified head injury to be a major cause of death and hospitalisation in Fiji. The predominance of males and road traffic-related injuries is consistent with studies on head injuries conducted in other low- and middle-income countries. The high fatality rate among those aged $30-44$ years in this study has not been noted previously. The high case fatality rate prior to admission to the hospital requires urgent attention.

Copyright $\odot 2012$ S. Karger AG, Basel

\section{Introduction}

Globally, head injury is a substantial cause of mortality and morbidity across all age groups, with a disproportionately greater burden borne by low- and middle-income

\section{KARGER \\ Fax +41613061234 \\ E-Mail karger@karger.ch}

www.karger.com (c) 2012 S. Karger AG, Basel

$0251-5350 / 12 / 0383-0179 \$ 38.00 / 0$

Accessible online at:

www.karger.com/ned
Dr. Bridget Kool

Section of Epidemiology and Biostatistics, School of Population Health

The University of Auckland, Private Bag 92019

Auckland 1142 (New Zealand)

Tel. +649923 3871, E-Mail b.kool@auckland.ac.nz 
countries [1]. In less-resourced settings, the burden of head injury is magnified by the high prevalence of risk factors and by health systems which are often unable to effectively deliver the acute and long-term care these patients require $[1,2]$. A recent review of the global impact of traumatic brain injury (TBI) identified that opportunities to adequately address this burden are compromised by limited epidemiological data on the causes and characteristics of these injuries [1]. This gap is particularly apparent in Pacific Island countries and territories which are infrequently the focus of global public health attention [3].

The Traffic-Related Injury in the Pacific Project was developed to understand the burden of injury in three Pacific nations - Fiji, Samoa, and Palau. The Fiji Injury Surveillance in Hospitals (FISH) system was established as part of this project to capture all fatal and serious nonfatal (hospitalised) injuries in Viti Levu, the main island of Fiji, during a 12-month period. Using this database, we describe the incidence and characteristics of head injuries resulting in hospital admission or death.

\section{Materials and Methods}

We conducted a population-based review of primary admissions to hospital $(>12 \mathrm{~h}$ ) or deaths as a result of a primary diagnosis of head injury identified from the FISH dataset during a 12-month period from October 1,2005, to September 30, 2006. The FISH system was piloted and refinements were made prior to the 12-month surveillance period [4]. Cases were classified as a 'head injury' if the medical notes described injuries to the head including intracranial injuries, skull fractures, and loss of consciousness.

FISH was established in all trauma-admitting hospitals on the island of Viti Levu, home to around $70 \%$ of Fiji's resident population (2007 census estimates 840,000) [5]. The two main ethnic groups on Viti Levu are the indigenous Fijians (i-Taukei, $\mathrm{n}=$ $353,895 ; 54.4 \%)$ and Indians $(n=260,008 ; 40.0 \%)$ [5]. The Fijian population has a younger age structure than the Indian population (0-14-year-olds 32.0 vs. $22.8 \%$ and $\geq 45$-year-olds 19.2 vs. $25.3 \%$, respectively).

A 1-page, 23-item injury surveillance form adapted from the WHO Injury Surveillance Guidelines [6] was used to collect data from patient folders and, where available, the electronic Patient Information System (PATIS). The information gathered included: demographic data (name, age, gender, and ethnicity), injury details (place of occurrence, activity, cause, intent, and alcohol and other substance use), length of stay, and outcome of injury event recorded in terms of nature of injuries and definitive outcome (dead on arrival, discharged, died while admitted).

Data collection was carried out by pathologists, hospital nurses, and final-year medical students located at the surveillance hospitals. Following data collection, the injury surveillance forms were checked and validated against patient folders and PATIS records, and the data were entered into Epi Info Version 3.3.2.

All data management and analysis were conducted using Microsoft Excel Version 12.1.7 statistical software. Age- and ethnic- specific rates for head injury fatalities and admissions to hospital were calculated per 100,000 for people resident in Viti Levu using the Fiji Bureau of Statistics 2007 census data [5]. Using the Fiji national population as the reference standard, comparisons of head injury rates by ethnicity and gender were age and gender standardised, as relevant. Results are presented as rates, means, and percentages with $95 \%$ confidence intervals (CI) where applicable.

Ethical approval for the study was obtained from the Fiji National Research Ethics Committee and the University of Auckland Ethics Committee. Analysis was conducted using anonymised data.

\section{Results}

During the 12-month injury surveillance period, 2,233 individuals either died or were admitted to hospital as a result of injury. Of these, 276 cases (12.4\%) had a primary diagnosis of head injury recorded in the FISH database. The overall rate of head injuries was 42.4/100,000 (95\% CI 37.7, 47.7). Over three quarters of cases were male (table 1). The age-standardised rate for males for all head injuries $(60.5 / 100,000(95 \%$ CI 52.1, 68.8)) was more than three times the female rate $(18.4 / 100,000$ (95\% CI 13.7, 23.1); $\mathrm{p}<0.001)$. More than half of those injured were indigenous Fijians. There were no significant differences in the agestandardised rate by ethnicity for the two leading ethnic groups (Fijian 40.3/100,000 (95\% CI 33.8, 46.9) vs. Indian 37.5/100,000 (95\% CI 30.1, 44.9)). Head injuries most commonly occurred among those aged 15-29 years, followed by children aged $0-14$ years; head injuries were least common among older adults (45 years and older). Of the three leading causes of injury, road traffic crashes had the highest rate of head injury $(16.1 / 100,000$ (95\% CI 13.1, 19.2)), followed by falls $(12.0 / 100,000$ (95\% CI 9.3, 14.6)) and 'hit by person or object' $(10.6 / 100,000$ (95\% CI 8.1, 13.1)).

\section{Deaths from Head Injury}

Fifty individuals died of head injury, equating to $20.3 \%$ of all injury deaths $(n=50 / 246)$, during the surveillance period. Two thirds $(n=33 / 50)$ of the head injury deaths occurred prior to arrival at the hospital. The median age of those who died was 31.5 years (range $0-78)$. The crude annualised fatality rate was 7.7/100,000 (95\% CI 5.6, 9.8) (table 1). The overall fatality rate for males was nearly four times that for females $(p<0.001)$. There were no significant differences in fatality rates by ethnicity between Fijians and Indians $(\mathrm{p}=0.85)$, the two main ethnic groups in Fiji (table 1). These differences remained not statistically different following age standardisation to the Fiji national population. The highest head injury fatality rate 
Table 1. Head injury incidence by gender, age group, ethnicity, and cause in Viti Levu, Fiji, from October 2005 to September 2006 $(\mathrm{n}=226)$

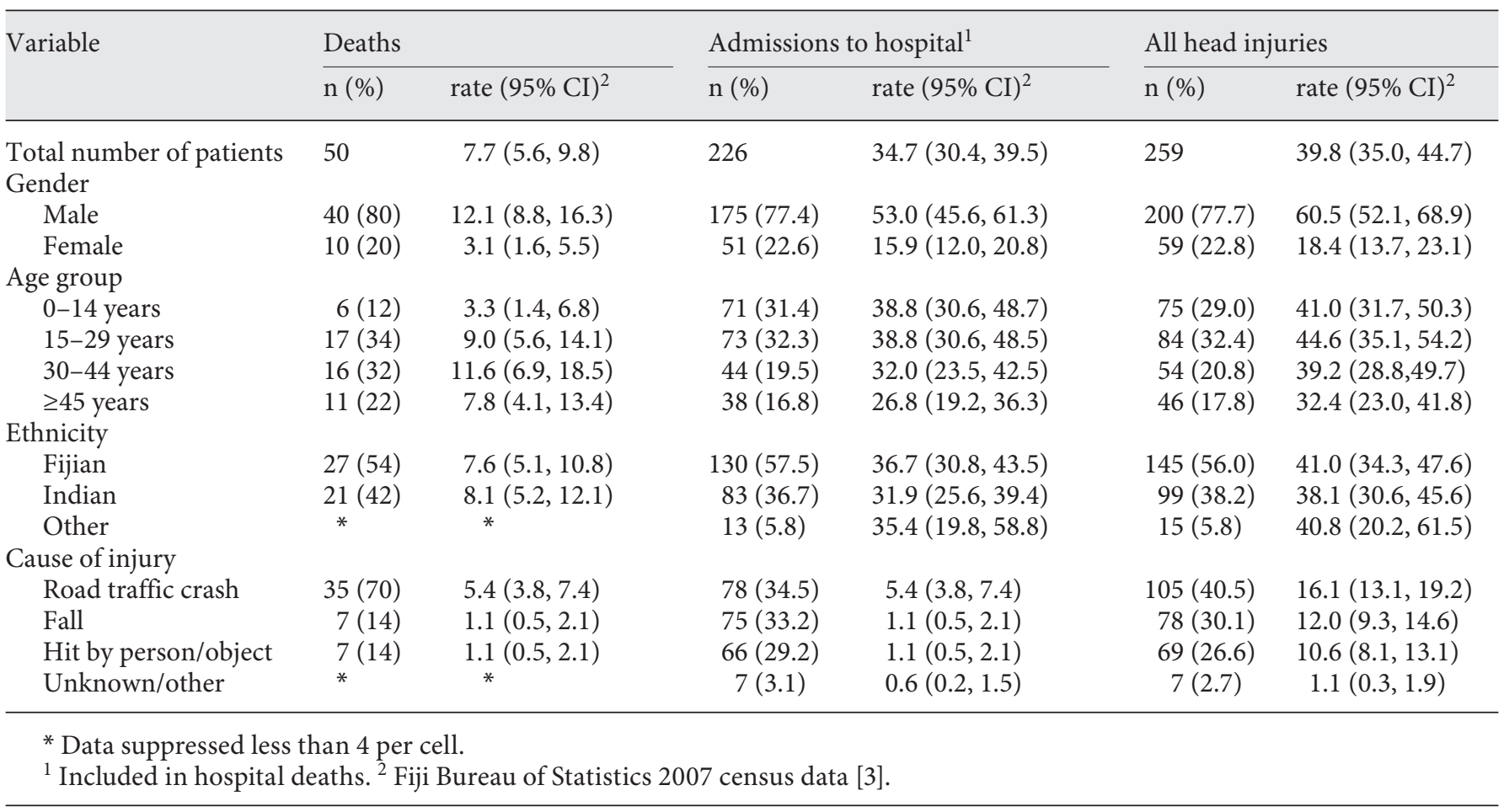

was seen among those in the 30-44-year age group, and the lowest was observed among children.

The leading external causes for head injury-related deaths in Fiji were road traffic crashes, followed by being 'hit by person or object' and falls (table 1). With the exception of 2 deaths due to falls, all head injury deaths among Indians $(n=19 / 21)$ resulted from road traffic crashes. Among Fijians, around one half of the head injury deaths were due to road traffic crashes $(n=14 / 27), 7$ were as a result of being 'hit by person or object' ( 5 of these were coded as 'intentional'), 5 were due to falls, and in 1 patient the cause of death was unknown.

'Travelling' was the most common activity at the time of injury, and 'highway/road/street' the most common location. Among fatal head injury cases aged 18 years and over, almost one third $(\mathrm{n}=14 / 44)$ were coded as likely to have involved alcohol. Information regarding potential alcohol use was 'unknown' in 10 cases.

\section{Admissions to Hospital as a Result of Head Injury}

During the 12-month injury surveillance period, 2,059 people in Fiji had an injury-related admission to hospital, of which $226(11.0 \%)$ were as a result of head injury, corresponding to an annual hospitalisation rate of 34.7/ 100,000 (95\% CI 30.4, 39.5) (table 1). The median age of patients admitted to the hospital with a head injury was 22.5 years (range $0-96$ ). The highest rates of admission to hospital were in the $0-14$ - and 15-29-year age groups. The injury hospitalisation rate for males was more than three times that for females $(p<0.001)$. The median length of hospital stay for those with head injuries as principal diagnosis was 2.0 days (range 1-107) compared to 3.0 days (range 0-161) for those without head injury. Eight percent of patients with a principal diagnosis of head injury died, compared to $3 \%$ of patients without this diagnosis ( $\mathrm{p}<$ $0.001)$.

The leading external cause for head injuries resulting in admissions to hospital were road traffic crashes followed by falls and 'hit by person or object' (table 1). Almost three quarters of head injuries due to 'hit by person or object' were recorded as intentional injuries $(n=47$, $72.0 \%$ ). Hospitalisation rates for head injury due to road traffic crashes, falls, and being 'hit by person or object' were almost three times higher in males than females (fig. 1). The greatest gender difference was seen for patients 'hit by person or object' in the 15-29-year age group 
Fig. 1. Head injury hospitalisation rate by gender and age groups (in years) for the three leading causes of injury in Viti Levu, Fiji, from October 2005 to September 2006 $(\mathrm{n}=231)$.

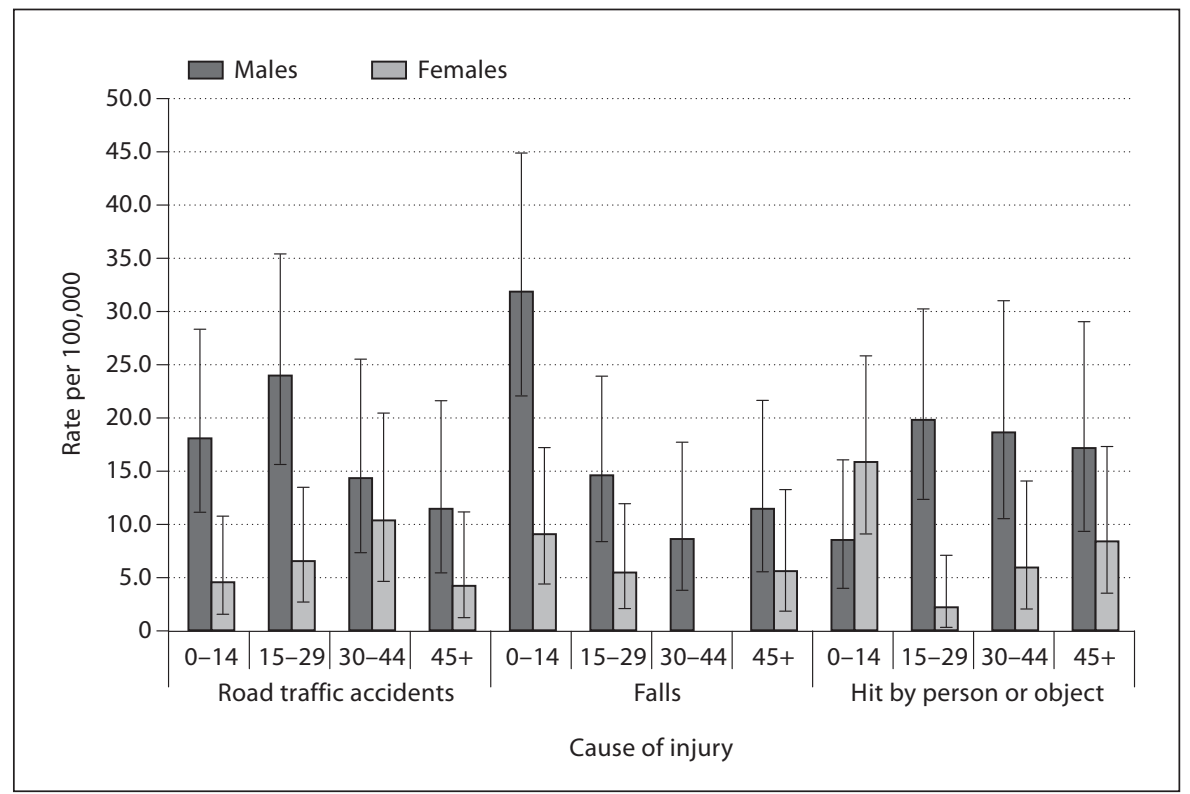

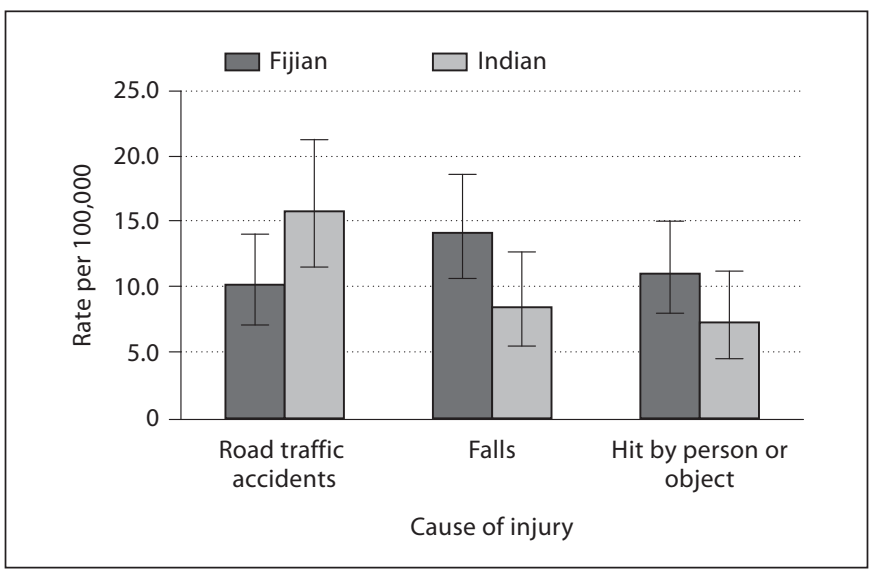

Fig. 2. Head injury hospitalisation rate by ethnicity (Fijian and Indian) for the three leading causes of injury in Viti Levu, Fiji, from October 2005 to September $2006(\mathrm{n}=219)$.

where rates were nine times greater among males than females (19.8 vs. $2.2 / 100,000)$. The cause of head injury differed by age group, with falls being the leading cause in 0 -14-year-olds $(20.8 / 100,000$ (95\% CI 14.9, 28.2)), road traffic crashes in 15-29-year-olds (15.4/100,000 (95\% CI $10.5,21.8)$ ), and 'hit by person or object' in those aged $30-44$ years and 45 years and older $(13.8 / 100,000$ (95\% CI $8.6,21.1)$ and $9.9 / 100,000$ (95\% CI 5.6, 16.1), respectively).

Overall, there were no significant differences in the rates of admission to hospital following a head injury be- tween the two major ethnic groups $(p=0.3)$ (table 1). These differences remained not statistically different following age standardisation to the Fiji national population. However, Fijians had higher rates of admissions to hospital for falls $(14.1 / 100,000$ (95\%CI 10.6, 18.5) vs. $8.5 / 100,000(95 \%$ CI $5.5,12.5))$ and 'hit by person or object' $(11.1 / 100,000(95 \%$ CI $7.8,14.9)$ vs. $7.3 / 100,000$ (95\% CI 4.5, 11.2)), and Indians had higher hospitalisation rates for road traffic crashes $(15.8 / 100,000$ (95\% CI 11.5, $21.2)$ vs. $10.2 / 100,000(95 \%$ CI 7.2, 13.9)) (fig. 2). As noted for deaths, road traffic crashes accounted for a higher proportion of hospital admissions due to a head injury among Indians $(\mathrm{n}=41,49.4 \%)$ than Fijians $(\mathrm{n}=36$, $27.7 \%)$. Over three quarters of 'hit by person or object' incidents among Fijians were coded as 'intentional' ( $\mathrm{n}=$ 30/39) compared to around two thirds of these incidents among Indians $(\mathrm{n}=13 / 19)$.

'Travelling' was the most common activity at the time of head injury resulting in hospital admissions, and 'highway/road/street' was the most common location for head injuries to occur. Males were most likely to sustain a head injury on the 'highway/road/street' ( $\mathrm{n}=76,43.4 \%$ ) followed by at home $(\mathrm{n}=54,30.9 \%)$. The reverse pattern was seen for females (at home $\mathrm{n}=24,47.1 \%$; on the 'highway/ $\mathrm{road} / \mathrm{street}$ ' $\mathrm{n}=22,43.1 \%$ ).

Among the 148 hospitalised head injury cases aged 18 years and over, $32(21.6 \%)$ were coded as likely to have involved alcohol. Information regarding potential alcohol use was 'unknown' in 32 cases. 


\section{Discussion}

In Viti Levu, Fiji, head injury accounts for around 12\% all of injury-related admissions to hospitals and for $20 \%$ of all injury-related deaths. Two thirds of deaths as a result of head injury occurred before arrival to the hospital. The in-hospital case fatality rate was much higher among patients with a principal diagnosis of head injury compared to those without ( 8 vs. $3 \%$ ). Road traffic crashes are the leading cause of head injury resulting in death and admissions to hospital. Males are overrepresented in both fatal and non-fatal head injuries. Among the two major ethnic groups, Fijians have higher rates of admissions to hospital for falls and 'hit by person or object', and Indians have higher hospitalisation rates for road traffic crashes. Alcohol use was likely to be involved in $22 \%$ of hospitalised head injury cases aged 18 years or older.

Data on the external causes of head injury in Pacific low- and middle-income countries are scant. The examination of population-based data in this study for both fatal and non-fatal moderate-to-severe head injuries by external causes, locations where the injury occurred, and activity at the time of injury provides insight into the characteristics and immediate outcomes of these events that can aid in the development of injury prevention and control programs in Fiji.

The findings of this review should be considered in light of some limitations. The review period of 12 months restricted the ability to examine trends in rates and causes of injury over time. The use of broad age bands limited the ability to investigate patterns of injury that may differ by age, for example infants and toddlers, preschool children, and school-age children. However, we were still able to contrast overall patterns of injury to published data. An important limitation of this study is that information on the socio-economic status or the site of injury or residence of the injured person with respect to urban/rural locality was not collected.

This study did not explore the magnitude of head injuries of all severities in Viti Levu. It is well established that the use of hospital-based data excludes people in the mild spectrum of head injury who are treated in a community setting or who do not seek medical attention [7, 8]. There is a possibility that some of those with moderate head injuries from the more socially disadvantaged and isolated areas may have not sought medical treatment or were treated in a community setting.

Only one injury was recorded for each individual (generally the most serious or life-threatening injury); therefore, patients with less severe head injuries or those

Hospitalised and Fatal Head Injuries in Viti Levu, Fiji with head injury as a component of more severe injuries to other body regions would not be apparent in these data. In addition, in $6.9 \%$ of the cases the nature of the injury was not specified, which is likely to have resulted in an underestimation of the actual burden of head injuries in Fiji.

Previous studies have identified differences in head injury outcomes between rural and urban settings $[9,10]$. A study from Nepal found that patients in rural areas took on average $30 \mathrm{~h}$ longer to obtain definitive neurosurgical care than their urban counterparts [11]. While the present study could not examine these differences, the limited availability of emergency medical facilities in rural Fiji mean these differences are also likely to exist in Fiji.

Our study found that head injuries resulting in hospital admissions or death were more common among males than females, a finding consistent with many other international studies [1, 12-18]. The higher head injury fatality rate among 30-44-year-olds in this study is in contrast to studies in middle- and high-income countries that have reported those aged 60 years and over experience the highest rates of TBI-related fatality $[1,19,20]$. The highest age-specific hospital incidence was noted among children and adolescents. This is consistent with other international studies [21, 22]. US data indicate children aged $0-4$ years and adolescents aged $15-19$ years are more likely to sustain a TBI resulting in an emergency department visit, hospital admission, and death combined than other age groups [21]. A South African study of hospital admissions for TBI reported the highest incidence among those aged 15-24 years [22]. Due to the relatively low numbers of cases in the older age groups (65 years and older) in the present study, these age groups were collapsed (45 years and over); therefore, we were unable to explore specific patterns of distributions in older adults. High TBI-related hospitalisation rates in the older age group have previously been noted in developed countries [19, 23, 24].

Road traffic crashes accounted for a substantial proportion of head injuries in this study, a finding consistent with previous studies from Pacific low- and middle-income countries $[15,25,26]$ as well as with other international studies from Australia [14], China [27], India [1, 28], Tunisia [29], and Italy [23]. A global review of TBIrelated outcomes reported that road traffic crashes accounted for $62 \%$ of these injuries [1]. In contrast, in Finland [30] and the USA [21] falls are the leading cause of injury resulting in head injury hospitalisation. Falls in the present study were the leading cause of head injuries in children resulting in hospital admissions (53.5\%), which 
is consistent with a Nepalese study reporting that $61 \%$ of hospital admission among children was due to falls [11].

The differences in the causes of head injury by ethnicity in the current study are curious. Fijians had higher rates of admissions to hospital for falls and 'hit by person or object' than Indians, while the hospitalisation rate for road traffic crashes was higher among Indians. Explanations for these differences could be many, including different lifestyles (e.g. Kava use among Fijians) and socioeconomic status, and are worthy of further exploration in aetiological studies.

The high proportion of head-injured individuals dying prior to arrival at hospital (66\%) in this study is of concern. Research indicates that nearly two thirds (65\%) of the mortality associated with head injury is due to secondary brain injury from hypertensive and hypoxic episodes [31]. High-quality emergency medical services and trauma systems in high-income countries have significantly improved the outcomes following injury $[32,33]$. A study investigating factors contributing to poor outcome in trauma patients in Pakistan identified multiple issues including inadequate pre-hospital care, inappropriate inter-hospital transfer, limited hospital resources, and an absence of integrated and organised trauma care [34]. Reviewing the access to and quality of pre-hospital and emergency care available to trauma patients in Fiji could help elucidate the issues underlying the observation of the high pre-hospital mortality found in this study.

\section{Conclusion}

In Fiji, head injury is an important public health problem with uncertain but potentially significant longerterm consequences. The findings of this study reveal the need for better data on long-term disabilities, trauma care and rehabilitations services, and, importantly, concentrated efforts to prevent head injuries, particularly those due to road traffic crashes, falls, and interpersonal violence.

\section{Acknowledgements}

This study was funded by an international collaborative research grant from the Wellcome Trust (UK) and the New Zealand Health Research Council. The authors gratefully acknowledge the support of the Permanent Secretary of Health, Dr. Lepani Waqatakirewa, and the Fiji Ministry of Health staff at national, divisional, and subdivisional levels, the doctors and nurses in the surveillance hospitals, and the final-year medical students of 20052006 at the Fiji School of Medicine.

\section{Disclosure Statement}

The authors have nothing to disclose.

\section{References}

$>1$ Hyder AA, Wunderlich CA, Puvanachandra P, Gururaj G, Kobusingye OC: The impact of traumatic brain injuries: a global perspective. Neurorehabilitation 2007;22: 341-353.

-2 Harris OA, Bruce CA, Reid M, Cheeks R, Easley K, Surles MC, Pan Y, Rhoden-Salmon D, Webster D, Crandon I: Examination of the management of traumatic brain injury in the developing and developed world: focus on resource utilization, protocols, and practices that alter outcome. J Neurosurg 2008;109: $433-438$.

$\checkmark 3$ Chandran A, Hyder AA, Peek-Asa C: The global burden of unintentional injuries and an agenda for progress. Epidemiol Rev 2010; 32:110-120.

4 Wainiqolo I, Kafoa B, McCaig E, Kool B, McIntyre R, Ameratunga S: Development and piloting of the Fiji Injury Surveillance in Hospitals system (trip project-1). Injury 2011, E-pub ahead of print.
5 Fiji Bureau of Statistics: 2007 Census Data. http://www.fijigov.fj (accessed June 17, 2011).

6 Holder Y, Peden M, Krug E, Lund J, Gururaj G, Kobusingye O: Injury Surveillance Guidelines. Geneva, World Health Organization, 2001, p 80.

7 Cassidy J, Carroll L, Peloso P, Borg J, von Holst H, Holm L, et al: Incidence, risk factors and prevention of mild traumatic brain injury: results of the WHO Collaborating Centre Task Force on Mild Traumatic Brain Injury. J Rehabil Med 2004;43(suppl):28-60.

$>8$ Carroll LJ, Cassidy JD, Holm L, Kraus J, Coronado VG: Methodological issues and research recommendations for mild traumatic brain injury: the WHO Collaborating Centre Task Force on Mild Traumatic Brain Injury. J Rehabil Med 2004;36:113-125.

$\checkmark 9$ Zhao Y, Wang W: Neurosurgical trauma in People's Republic of China. World J Surg 2001;25:1202-1204.
10 Gabella B, Hoffman RE, Marine WW, Stallones L: Urban and rural traumatic brain injuries in Colorado. Ann Epidemiol 1997; 7: 207-212.

11 Mukhida K, Sharma M, Shilpakar S: Pediatric neurotrauma in Kathmandu, Nepal: implications for injury management and control. Childs Nerv Syst 2006;22:352-362.

12 Tagliaferri F, Compagnone C, Korsic M, Servadei F, Kraus J: A systematic review of brain injury epidemiology in Europe. Acta Neurochir (Wien) 2006;148:255-268.

13 Rutland-Brown W, Langlois JA, Thomas KE, $\mathrm{Xi}$ YL: Incidence of traumatic brain injury in the United States, 2003. J Head Trauma Rehabil 2006;21:544-548.

- 14 Myburgh JA, Cooper DJ, Finfer SR, Venkatesh B, Jones D, Higgins A, Bishop N, Higlett T: Epidemiology and 12-month outcomes from traumatic brain injury in Australia and New Zealand. J Trauma 2008;64: 854-862. 
15 Matthew PK, Kapua F, Soaki PJ, Watters DA: Trauma admissions in the southern highlands of Papua New Guinea. Aust NZ J Surg 1996;66:659-663.

$>16$ McKinlay A, Grace RC, Horwood LJ, Fergusson DM, Ridder EM, MacFarlane MR: Prevalence of traumatic brain injury among children, adolescents and young adults: prospective evidence from a birth cohort. Brain Inj 2008;22:175-181.

-17 Barker-Collo SL, Wilde NJ, Feigin VL: Trends in head injury incidence in New Zealand: a hospital-based study from 1997/1998 to $2003 / 2004$. Neuroepidemiology 2009;32 $32-39$.

$>18$ Thurman D, Guerrero J: Trends in hospitalization associated with traumatic brain injury. JAMA 1999;282:954-957.

19 Engberg AW, Teasdale TW: Traumatic brain injury in Denmark 1979-1996. A national study of incidence and mortality. Eur J Epidemiol 2001;17:437-442.

20 Tiret L, Hausherrr E, Thicoipe M, Garros B, Maurette P, Castels J, Hatton F: The epidemiology of head trauma in Aquitaine (France), 1986: a community-based study of hospital admissions and deaths. Int J Epidemiol 1990; 19:133-139.

21 Langlois JA, Rutland-Brown W, Wald MM: The epidemiology and impact of traumatic brain injury: a brief overview. J Head Trauma Rehabil 2006;21:375-378.
22 Nell V, Brown DS: Epidemiology of traumatic brain injury in Johannesburg - II. Morbidity, mortality and etiology. Soc Sci Med 1991; 33:289-296.

23 Baldo V, Marcolongo A, Floreani A, Majori S, Cristofolettil M, Dal Zotto A, Vazzoler G, Trivello R: Epidemiological aspect of traumatic brain injury in Northeast Italy. Eur J Epidemiol 2003;18:1059-1063.

24 Andelic N, Sigurdardottir S, Brunborg C, Roe C: Incidence of hospital-treated traumatic brain injury in the Oslo population. Neuroepidemiology 2008;30:120-128.

25 Sinha SN, Sengupta SK: Road traffic accident fatalities in Port Moresby: a ten-year survey. Accid Anal Prev 1989;21:297-301.

26 Sinha SN, Sengupta SK, Purohit RC: A five year review of deaths following trauma. PNG Med J 1981;24:222-228.

27 Wu X, Hu J, Zhuo L, Fu C, Hui G, Wang Y, Yang W, Teng L, Lu S, Xu G: Epidemiology of traumatic brain injury in eastern China, 2004: a prospective large case study. J Trauma 2008;64:1313-1319.
28 Tabish A, Lone NA, Afzal WM, Salam A: The incidence and severity of injury in children hospitalised for traumatic brain injury in Kashmir. Injury 2006;37:410-415.

29 Bahloul M, Chelly H, Ben Hmida M, Ben Hamida C, Ksibi H, Kallel H, Chaari A, Kassis M, Rekik N, Bouaziz M: Prognosis of traumatic head injury in South Tunisia: a multivariate analysis of 437 cases. J Trauma 2004;57:255-261.

30 Koskinen S, Alaranta H: Traumatic brain injury in Finland 1991-2005: a nationwide register study of hospitalized and fatal TBI. Brain Inj 2008;22:205-214.

31 Chesnut R, Marshall L, Klauber M, Blunt B, Baldwin N, Eisenberg H, Jane J, Marmarou A, Foulkes M: The role of secondary brain injury in determining outcome from severe head injury. J Trauma 1993;34:216-222.

32 Smith J, Martin L, Young W, Macioce DP: Do trauma centers improve outcome over nontrauma centers: the evaluation of regional trauma care using discharge abstract data and patient management categories. J Trauma 1990;30:1533-1538.

33 Roy P: The value of trauma centres: a methodologic review. Can J Surg 1987;30:7-22.

-34 Jat AA, Khan MR, Zafar H, Raja AJ, Hoda Q, Rehmani R, Lakdawala RH, Bashir S: Peer review audit of trauma deaths in a developing country. Asian J Surg 2004;27:58-64. 